\title{
THE ELLIS-GOHBERG INVERSE PROBLEM FOR MATRIX-VALUED WIENER FUNCTIONS ON THE LINE
}

\author{
M. A. KaAShoEK And F. VAn Schagen
}

\begin{abstract}
This paper deals with the Ellis-Gohberg inverse problem for matrix-valued Wiener functions on the line, instead of on the circle, as was done in [4] for scalar functions and in [14] for matrix-valued functions. The problem is reduced to a linear finite matrix equation of which the right hand side is described explicitly in terms of one of the given functions. The results obtained parallel and extend those derived in [14] for Wiener functions on the circle. Special attention is paid to the case when the given functions are Fourier transforms of functions of finite support. In the final section the results are specified further for the case when the given functions are rational matrix functions.
\end{abstract}

Mathematics subject classification (2010): 47A56, 47B35, 47A48, 93B15, 15A06.

Keywords and phrases: Inverse problem, Wiener function on the line, Hankel operator, Wiener-Hopf integral operator, convolution operator on a finite interval, bi-inner rational matrix function, realization.

\section{REFERENCES}

[1] H. Bart, I. Gohberg, M. A. KaAshoek And A. C. M. Ran, A state space approach to canonical factorization, Birkhäuser Verlag, Basel, 2010.

[2] M. J. Corless AND A. E. Frazho, Linear systems and control, An operator perspective, Marcel Dekker, Inc, New York, 2003.

[3] R. L. ELLIS, An Identity Satisfied by Certain Orthogonal Vector-Valued Functions, in A Panorama of Modern Operator Theory and Related Topics. The Israel Gohberg Memorial Volume, OT 218, Birkhäuser Verlag, Basel, 2012, pp. 329-344.

[4] R. L. Ellis And I. Gohberg, Orthogonal systems related to infinite Hankel matrices, J. Functional Analysis 109 (1992), 155-198.

[5] R. L. Ellis AND I. GohBerg, Orthogonal systems and convolution operators, OT 140, Birkhäuser Verlag, Basel, 2003.

[6] R. L. Ellis, I. GohBerg, AND D. C. LAY, Infinite analogues of block Toeplitz matrices and related orthogonal functions, Integral Equations and Operator Theory 22 (1995), 375-419.

[7] A. E. Frazho, M. A. Kahshoek, And A. C. M. Ran, Rational Matrix Solutions of a Bezout Type Equation on the Half-plane, in: Advances in Structured Operator Theory and Related Areas. The Leonid Lerer Anniversary Volume, Oper. Theory Adv. Appl. 237, Springer Basel AG 2012, pp. $145-160$.

[8] I. Gohberg, S. Goldberg, And M. A. KaAshoek, Classes of Linear Operators, Volume I, Birkhäuser Verlag, Basel, 1990.

[9] I. Gohberg, S. Goldberg, And M. A. KaAshoek, Classes of Linear Operators, Volume II, Birkhäuser Verlag, Basel, 1993.

[10] I. Gohberg, M. A. KaAshoek and F. van Schagen, Partially Specified Matrices and Operators: Classification, Completion, Applications, Birkhäuser Verlag, Basel, 1990.

[11] C. Heij, A. C. M. Ran And F. van Schagen, Introduction to Mathematical Systems Theory, Birkhäuser Verlag, Basel, 2007.

[12] M. A. KAASHOEK AND F. VAN SCHAGEN, Ellis-Gohberg identities for certain orthogonal functions I: Block matrix generalizations and $\ell^{2}$-setting, Indag. Math. 23 (2012) 777-795. 
[13] M. A. KAASHOEK AND F. VAN SCHAGEN, Ellis-Gohberg identities for certain orthogonal functions II: Algebraic setting and asymmetric versions, West Memorial Issue, Proc. Math. Royal Irish Acad., 113A (2) (2013), 107-130.

[14] M. A. KAAShOEK AND F. VAn SChagen, The inverse problem for Ellis-Gohberg orthogonal matrix functions, Integral Equ. Oper. Theory 80 (2014), 527-555.

[15] M. G. KREIN, On the distribution of the roots of polynomials which are orthogonal on the unit circle with respect to an alternating weight, Teor. Functsiĩ Funkstional Anal. i Prlozhen. 2 (1966) 131-137, (in Russian).

[16] P. Lancaster and L. Rodman, Algebraic Riccati Equations, Oxford University Press, Oxford, 1995.

[17] P. Lancaster and M. Tismenetsky, The Theory of Matrices, Academic Press, Orlando, 1985.

[18] S. LANG, Algebra, Addison-Wesley Publ. Co, Reading MA, 1965.

[19] V. V. PELlER, Hankel operators and their applications, Springer-Verlag, New York, 2003.

[20] E. D. SonTAG, Mathematical Control Theory, Springer-Verlag, New York, 1998. 